\title{
Maximum Allowable Service Pressure for Steel Pipes Used for Transport of Hydrogen Pure or Blended with Natural Gas
}

\author{
Jamie Kuk Anak Mijim ${ }^{1}$, Guy Pluvinage 2* $^{*}$ \\ ${ }^{1}$ University of Lorraine, Metz, Moselle, France \\ ${ }^{2}$ FM.C Silly sur Nied, Moselle, France \\ E-mail: pluvinage.guy@orange.fr
}

Received: 12 August 2020; Revised: 18 October 2020; Accepted: 29 October 2020

\begin{abstract}
The addition of hydrogen in natural gas could have an impact on the degradation over time of the materials currently used for the storage, transport, distribution and use of natural gas. The compatibility of these materials with natural gas including of hydrogen is dependent on the proportion of hydrogen added to the gas and is assessed with regard to several criteria: Permeation of hydrogen through metallic materials; loss of integrity of these materials and adaptation of follow-up actions in service, surveillance and maintenance of equipment. This paper is devoted to the effect of hydrogen embrittlement (HE) by adding hydrogen into natural gas network on design, maintenance, supervision and maximum allowable operating pressure (MAOP) for smooth and damaged pipes.
\end{abstract}

Keywords: hydrogen, embrittlement, pipes, design, maintenance

\section{Nomenclature}

$\begin{array}{ll}\mathrm{d} & \text { distance } \\ \mathrm{e} & \text { thickness } \\ \mathrm{f}_{0} & \text { design factor } \\ \mathrm{f}_{0 . \mathrm{prob}, \text { MAOP }} & \text { partial design factor } \\ \mathrm{q} & \text { flow rate of the leak } \\ \mathrm{n} & \text { adiabatic coefficient of hydrogen } \\ \mathrm{p} & \text { pressure } \\ \mathrm{p}_{\mathrm{s}} & \text { service pressure } \\ \mathrm{p}_{\mathrm{ar}} & \text { arrest pressure } \\ \mathrm{p}_{0} & \text { atmospheric pressure } \\ \mathrm{q} & \text { flow rate } \\ \mathrm{r} & \text { radial distance between the fire and the place of interest } \\ \mathrm{A}_{\mathrm{h}} & \text { area of the leak } \\ A_{p} & \text { pipe section } \\ \mathrm{C}_{\mathrm{D}} & \text { rejection coefficient } \\ \mathrm{C}_{\mathrm{H}} & \text { hydrogen concentration }\end{array}$

Copyright (C2020 G Pluvinage, et al.

DOI: https://doi.org/10.37256/est.212021583

This is an open-access article distributed under a CC BY license

(Creative Commons Attribution 4.0 International License)

https://creativecommons.org/licenses/by/4.0/ 


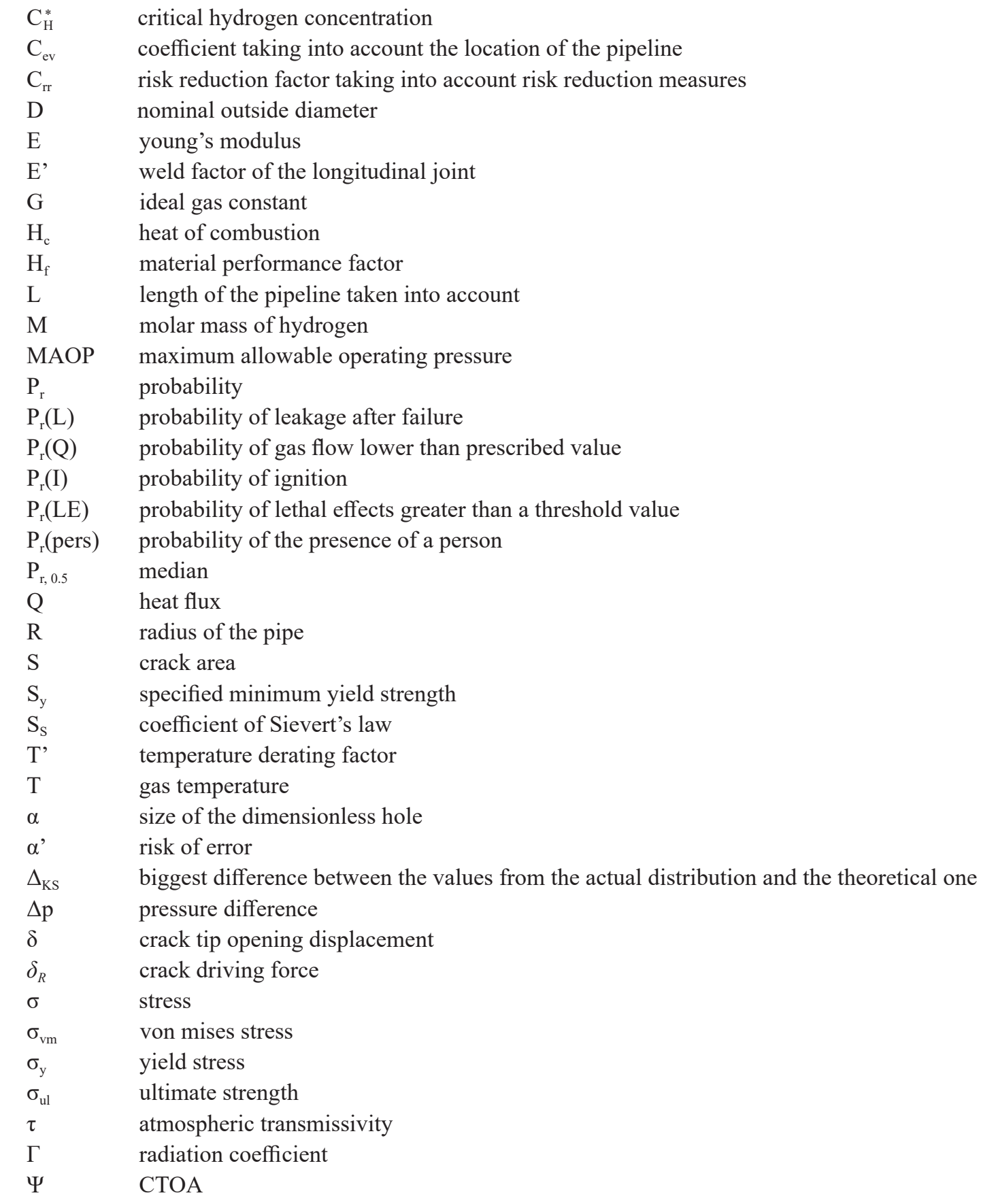

\section{Introduction}

Hydrogen economy considers hydrogen as a substantial fraction of a country's energy and services. This could happen in the future if hydrogen can be produced from domestic energy sources economically and in an environmentalfriendly manner. Fuel cell vehicles are now technically mature and potentially affordable and can gain market share in competition with conventional power generation sources and transportation vehicles. This would reduce dependence on oil and coal as the major sources of energy and improved environmental quality through lower carbon emissions. Many technical, social, and policy challenges must be overcome to ensure the transition to such economy can take place. Hydrogen is used as a sustainable energy carrier for electric fuel cell vehicles (EFCV) and as a means of storing 
renewable energy. Hydrogen can also be used as fuel in stationary fuel cell systems for buildings, emergency power or distributed generation.

Hydrogen transport is generally made by pipelines. This solution is preferable over transport on the road by truck for safety reasons. Pure hydrogen is transported via pipelines. The introduction of hydrogen into the existing pipeline network has been proposed as a mode of transporting renewable energy from the production site to the consumers systems such as large wind farms. If mixed with relatively low concentration about less than 5\%-15\% of hydrogen by volume, this solution is viable on condition that the risks associated with the use of the gas mixture in end-use devices (such as household appliances), general public safety or the sustainability and integrity of the existing network of pipelines are not significantly affected [1]. Any introduction of a hydrogen mixture would require modifications to the design, monitoring and maintenance practices of existing networks.

First reason, which increases of attention to the problem hydrogen degradation of pipeline steels, is fact that hydrogen will play a decisive role in a future energy system [2], [3]. The possible use of existing pipeline networks for mixtures of natural gas and hydrogen offers a unique and cost-effective opportunity to initiate the progressive introduction of hydrogen as part of the development of a full hydrogen energy system [2]-[4].

Second is the fact that specific long term exploitation of pipelines promotes of steel hydrogenating process. First of all, pipeline steels encounter hydrogen during transport of sour crude oil and other petroleum products [5]. During transport, Magnin [6], affirm that hydrogenation of pipe wall metal can be possible from inside because of hydrogen isolation due the chemical reaction of condensed aqueous solution contained hydrocarbonate ions, with metal. Moreover, external environmental conditions cause free corroding processes, where hydrogen can evaluate on metal surface as result of cathodic counterpart of the anodic dissolution reaction. This fact has been proved by several studies [7], [8].

When comparing to the risk posed by natural gas, pure or blended hydrogen transport related component induces the following problems:

-Hydrogen presents a wider range of flammable concentration which increase the likelihood of ignition and resulting damage;

-Durability of metallic pipes is affected when exposed to hydrogen for long periods, with higher hydrogen concentration in operating at high pressure by a phenomenon so-called hydrogen embrittlement (HE).

$\mathrm{HE}$ is the description commonly given to a range of different phenomena, which have the common characteristic that there is a decrease of mechanical properties of the steels by a relatively small concentration of hydrogen. These phenomena are to be caused different mechanisms. The macroscopic manifestations of these two phenomena are (a) a decrease of ductility and fracture toughness and (b) slow crack growth under service pressure.

This effect strongly depends on steel strength and must be assessed on a case-by-case basis mainly for high strength steels. However, the pipe steels in transport systems are mainly made of medium resistance steels, typically API 5L X52, which are quite sensitive to embrittlement induced by hydrogen under normal operating conditions.

For low-strength and medium-strength steels, there may be a decrease in ductility and fracture toughness with essentially no decrease in yield stress and ultimate strength, and with no subcritical crack growth.

Hydrogen embrittlement also induces large scatter of mechanical properties. To take this fact into account, an increase of the design safety factors is necessary. This needs to carry out at also the following three levels: design, maintenance and surveillance of pipelines carrying pure and mixed hydrogen.

Pipeline design ensures that failure occurs when the strength capacity of the pipe steel is exceeded. Design consists of verifying that the membrane stress does not exceed the admissible stress define as the material strength divided by a safety factor. In codes, this approach is slightly different as the acceptable service pressure has to be lower than the value of the maximum allowable operating pressure (MAOP). In this paper, a new approach of the computing of MAOP is presented. The originality is to approach the problem from a probabilistic and non-deterministic point of view because of the above-mentioned increase of scatter of material properties under HE [2].

\section{Hydrogen embrittlement}

In the year 1875, Johnson [3] revealed extraordinary changes in the failure strain of iron which was temporarily 
immersed in acid for just a few minutes. He also observed that the change is not permanent because "over time, the metal slowly regains its original strength". He further observed that the moistened fracture surface of a weakened steel released gas bubbles. In the same article, he indicates that a high strength steel has a greater loss of toughness due to acid immersion than a mild steel.

Hydrogen can be introduced into oil and gas installations by contamination during manufacturing processes, during treatments such as carbonization, cleaning, pickling, phosphating, electrochemical cleaning, electroplating, during manufacturing during profiling, machining and drilling (lubricating effect, welding) or brazing. It can be present in structural elements under cathodic protection such as pipes and tanks for the storage and transport of crude oil.

Stress-strain curves were obtained from test pieces made of API 5L X52 steel in hydrochloric acid solutions respectively $1.2 \mathrm{M} / 1 \mathrm{HCl}$. The immersion time was 7 days at a temperature of $298 \mathrm{~K}$. Table 1 shows the tensile properties (yield strength $\sigma_{y}$, ultimate strength $\sigma_{u l}$, Young's modulus E and elongation A\%) after immersion .

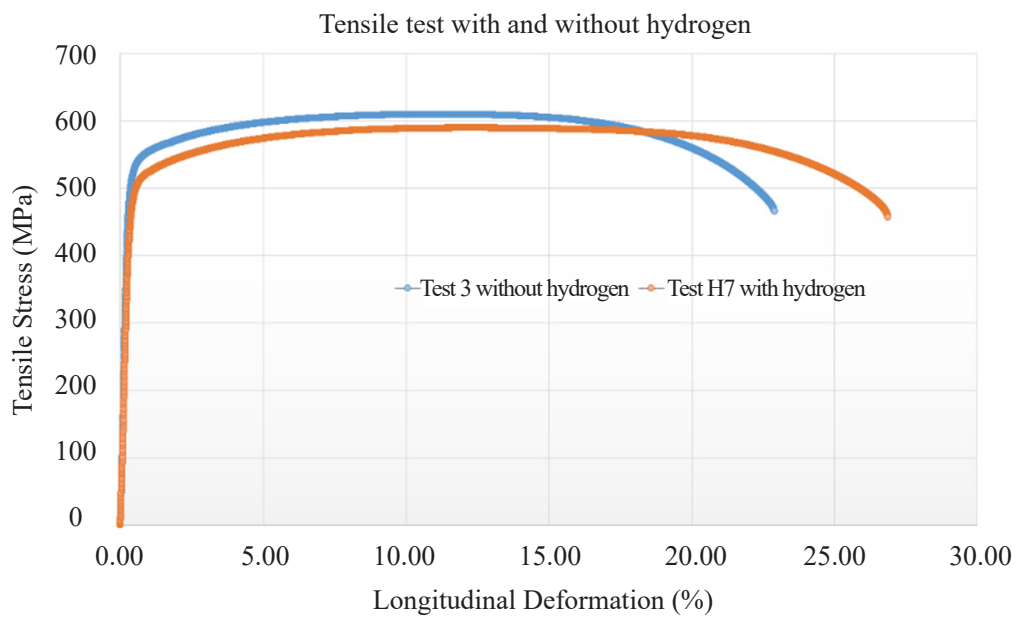

Figure 1. Stress-strain curves for API 5L X52 steel in hydrochloric acid solution $(1.2 \mathrm{M} / 1 \mathrm{HC})$ and in airl

Table 1. Tensile properties of API 5L X52 steel after immersion in hydrochloric acid

\begin{tabular}{ccc}
\hline Solution & air & $\mathrm{HCl}$ \\
& $1.2 \mathrm{M} / 1$ \\
\hline $\mathrm{E}(\mathrm{GPa})$ & 196 & 181 \\
$\sigma_{y}(\mathrm{MPa})$ & 397 & 405 \\
$\sigma_{u l}(\mathrm{MPa})$ & 527 & 511 \\
$\mathrm{~A} \%$ & 32.5 & 17.5 \\
$\sigma_{y} / \sigma_{u l}$ & 75.2 & 79.2 \\
\hline
\end{tabular}

After immersion in hydrochloric acid, the failure $\mathrm{A} \%$, the fracture energy $K_{V}$ and the fracture toughness $\mathrm{J}_{\mathrm{c}}$ are greatly degraded. The yield strength and the ultimate strength are much less so, Figure 1 . These changes in mechanical properties are attributed to hydrogen embrittlement.

The distinct stages associated with the whole process of metal hydrogen introduction are:

-The first hydrated atoms are transported in a double layer on the surface, a separation of hydrogen in proton form and water by adsorption, the electron donation of the material produce a discharge.

-The process of combining hydrogen can occur in three ways: atom to atom or atom to ion or both.

-The ultimate stage is desorption and entry into the material, with an evolutionary reaction of hydrogen which results in the formation and diffusion of hydrogen. 
Because hydrogen atom is small, it can move easily between the crystalline sites. Hydrogen diffuses into steels according to conventional hetero-diffusion mechanisms with infinite dilution. Fick's laws are directly applicable to the temperatures usual for this type of diffusion in the absence of transport force. Transport of hydrogen atoms by dislocation forms the basis of certain embrittlement mechanisms. It supposes the existence of hydrogen trapping by dislocations and the accelerated transport of hydrogen atoms by mobile dislocations. The increase in the rate of dislocation by hydrogen is attributed to the hydrogen atmosphere associated with the dislocation effectively protecting its interaction with places under elastic stress [4].

All solid materials contain structural defects. Crystalline solids such as metallic materials contain imperfections such as pores, dislocations, grain boundaries, pores, inclusions, etc. These defects can serve as trapping sites for hydrogen. Certain impurities or alloying elements can also act as trapping sites. In some cases, they form hydrides with carbon and sulphur. These can preferentially interact with hydrogen to form gases such as $\mathrm{CH} 4$ and $\mathrm{H} 2 \mathrm{~S}$ and generally lead to blistering in the material. The consequence of trapping is the reduction in the rate of hydrogen transport through the material. When hydrogen builds up on these defects, the subsequent diffusion of hydrogen becomes difficult while for hydrogen, the residence time on these sites increases compared to a normal distribution in the network.

When hydrogen enters the material, it tends to accumulate in a wide variety of locations within microstructures such as on grain boundaries, inclusions, voids, dislocation tangles and dislocation networks, atoms in solute as well as in a solid solution. No matter where hydrogen is fixed, the rupture will be controlled by the magnitude of the effects of hydrogen, although in general all sites will see hydrogen build up but to different degrees.

The number of hydrogen trapping sites is particularly important for "vintage" pipe steels Steels produce before the 70's have relatively high inclusions content and are therefore more sensitive to HE.

To explain embrittlement by hydrogen, several mechanisms are invoked, namely:

- Weakening of the metal-metal atomic bonds [5],

- Modification of plasticity,

- Decohesion competition/emission of dislocations [6],

- Molecular recombination in defects [7],

- Stress triaxiality.

\subsection{Weakening of metal-to-metal atomic bonds}

Two models dealing with the effects of hydrogen on the cohesion forces have been proposed by Steigerwald et al. [5] and Oriani [8].

These models assume a local decrease in the cohesive force of the atomic network due to the hydrogen present in the matrix or at the grain boundaries (or any other metallurgical defects). A crack can then propagate when the applied (tensile) stress is sufficient to counterbalance the cohesive force of the lattice, modified by the presence of hydrogen. Nevertheless, the decrease in the cohesive force is a postulate and no experimental evidence really exists to justify it. One can conceive of an effect of hydrogen on the macroscopic rupture deformation of a system which can contain a large concentration of hydrogen via a reduction in cohesion forces. This hypothesis is much advanced in the case of metals whose hydrogen solubility is very low as it is the case for centered cubic steels (CCS).

Sofronis et al. [9] proposed a model in which the hydrogen concentration is sensitive to hydrostatic pressure. The dissolved hydrogen in metals and alloys resides either in interstitial sites of the network or reversible trapping sites such as microstructure defects generated by plastic deformation such as dislocations.

Capelle et al. [10] studied the ductile-brittle transition on 3 steels from pipes X52, X70 and X100. They electrolytically charged "Roman tile" test specimen in order to introduce hydrogen, the concentration of which was determined by anodic discharge. 


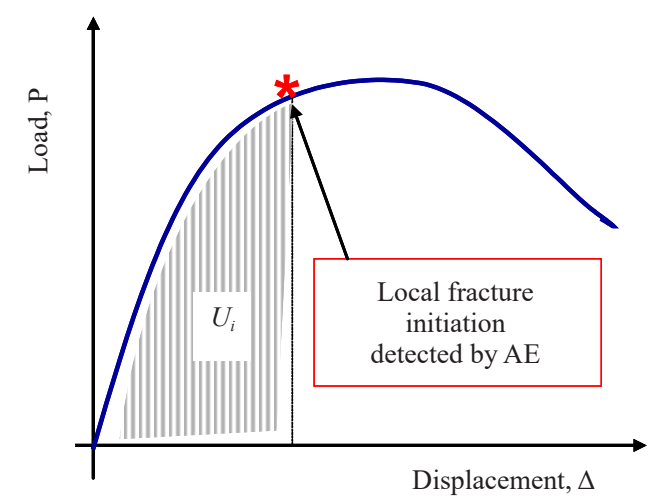

Figure 2. Definition of the fracture energy on a charge-displacement curve [10]

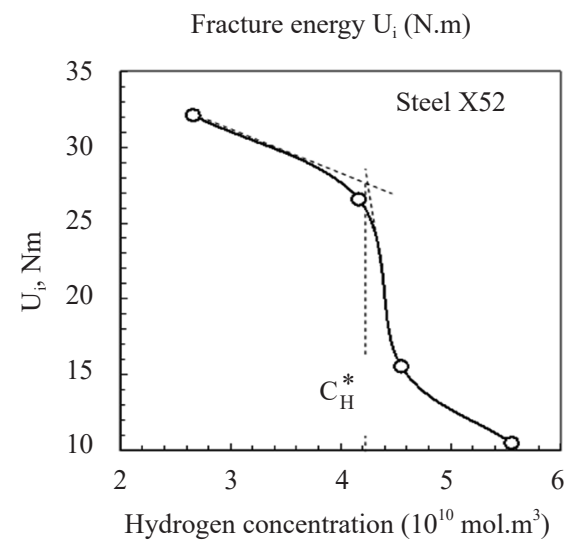

Figure 3. Determination of critical hydrogen concentration for API 5L X52 steel [10]

After exposure for a fixed period under the hydrogenation conditions, the test pieces were loaded until failure under increasing static load, according to a 3-point bending scheme. The "load-displacement" and "acoustic emission" (AE) diagrams were recorded simultaneously during the tests. The initiation of the rupture was defined by the acoustic emission method.

The fracture resistance in presence of hydrogen is defined as the area under the load-displacement curve up to the load at ignition. The scheme for determining the parameter $\mathrm{U}_{\mathrm{i}}$ is presented in Figure 2.

Table 2. Critical hydrogen concentrations $\mathrm{C}_{\mathrm{H}}^{*}$ for 3 pipe steels

\begin{tabular}{cc}
\hline steel & $C_{H}^{*} 10^{10} \mathrm{~mol} / \mathrm{m}^{3}$ \\
\hline $\mathrm{X} 52$ & 4.3 \\
$\mathrm{X} 70$ & 2.3 \\
$\mathrm{X} 100$ & 1.5 \\
\hline
\end{tabular}

The evolution of fracture strength as $\mathrm{U}_{\mathrm{i}}$ versus hydrogen concentration is given in Figure 3 for the 3 pipe steels API $5 \mathrm{~L}$ X52, X70 and X100.

The main observation based on these results is the existence of a certain critical exposure time and therefore a critical concentration of hydrogen for which a significant decrease in fracture toughness is observed. The values of this critical concentration are given in Table 2 . 
It should be noted that the definition of "critical concentration" is often used in studies of hydrogen problems in metals and alloys, but with a different physical meaning.

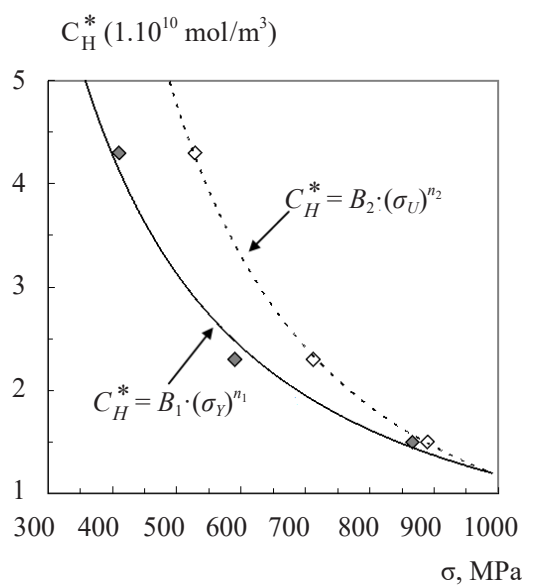

Figure 4. Critical concentration of hydrogen in API X52, X70 and X100 quality pipeline steels as a function of the yield strength and ultimate stress [11]

The comparative evaluation of this critical concentration for the pipe steels studied shows a tendency to a monotonous decrease in values with the increase in the elastic limit or the ultimate stress (Figure 4). This dependence can be described by a power function. As a first approximation, we can conclude that:

$$
C_{H}^{*} \sim 1 / \sigma_{u}^{2}
$$

\subsection{Hydrogen concentration at crack tip}

A calculation of the hydrogen concentration was carried out using the following pipe geometry diameter $219 \mathrm{~mm}$ thickness $6.1 \mathrm{~mm}$ with the Sofronis model [11]. The pipe is exhibits an external surface notch of depth equal to half the thickness with a notch radius of $0.25 \mathrm{~mm}$ and a notch angle of $45^{\circ}$. The boundary conditions used are:

The hydrogen flow $\mathrm{J}$ is zero on the symmetry faces of the pipe,

The hydrogen concentration on the inner wall of the pipe is given by Sievert's law:

$$
C_{H}=\mathrm{S}_{\mathrm{S}} \sqrt{\Delta \mathrm{p}}
$$

With: $\mathrm{c}$ the hydrogen concentration (atoms $\times \mathrm{m}^{3} . \mathrm{S}_{\mathrm{s}}$ the coefficient of Sievert's law $\left(6.59 \times 10^{18}\right.$ atoms $\left.\times \mathrm{m}^{-3} \times \mathrm{Pa}^{-1 / 2}\right)$, and $\Delta \mathrm{p}$ the pressure difference $(\mathrm{Pa})$.

The initial concentration on the outer wall of the tube is zero, the pressure outside the tube is 1 bar. A hydrogen gas pressure of 60 bar is applied for $72 \mathrm{~h}$. Figure 5 gives the profile of the concentration in the thickness of the pipe (far from the defect). A 17/1 ratio of maximum value (internal wall) and minimum value (external wall) is noted. 


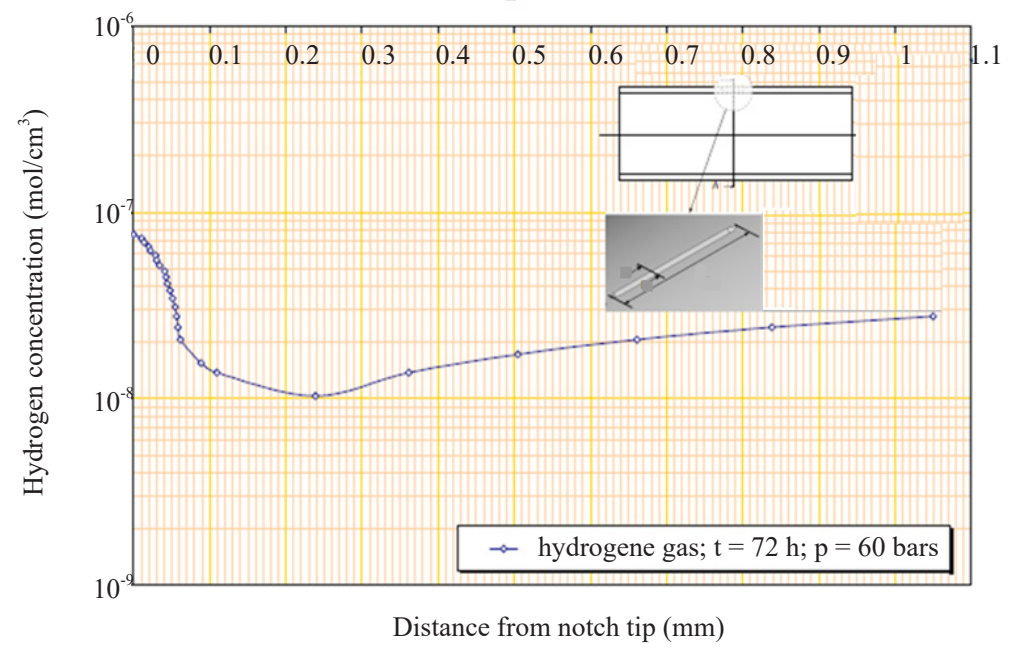

Figure 5. Evolution of the hydrogen concentration in the thickness of the tube [11]

The notch effect, which significantly increases the stress triaxiality at this location, is also very influential in terms of the hydrogen concentration. The concentration at the bottom of the notch is 44 times greater than that found at the outer wall of the pipe and 2.5 times more than at the inner wall. High hydrogen concentration is effective only over a very short distance, of the order of $56 \mu \mathrm{m}$. This tends to support micrographic observations, obtained following bursting tests showing a change in the rupture mechanism, over a distance of the same order of magnitude.

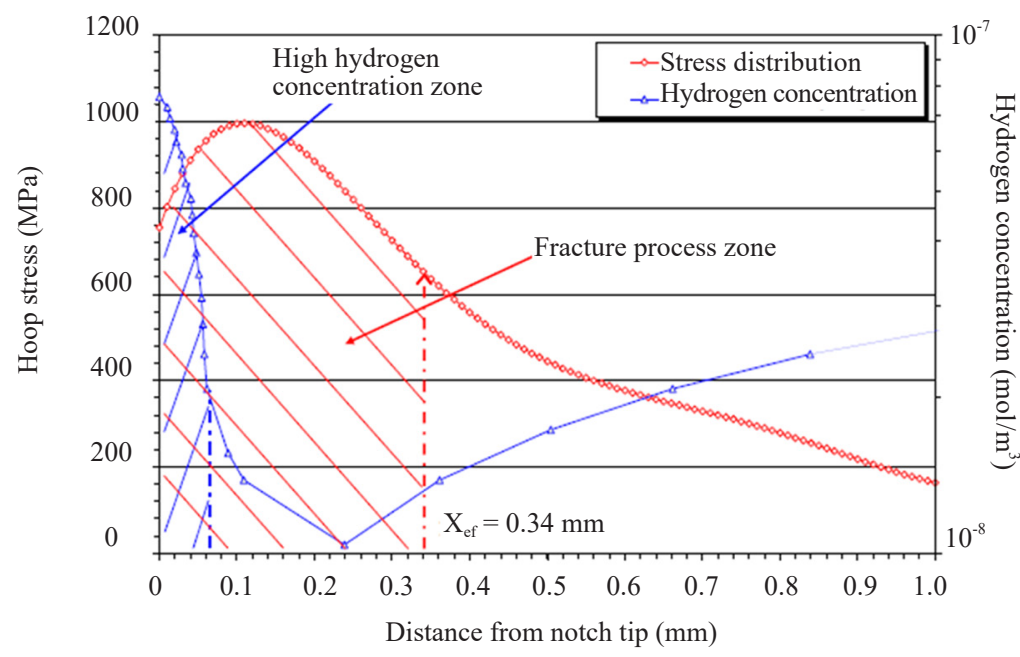

Figure 6. Hydrogen concentration and stress distribution along ligament ahead of notch [11]

The application of the volumetric method, on circumferential stress distribution ahead of notch, gives the volume of rupture process, Figure 6 . The volume of high hydrogen concentration is defined as the area where the concentration remains above the maximum value found in the tube away from the notch.

Figure 6 shows that the volume, where the hydrogen concentration is highest, is much smaller than the volume of fracture process. This explains that the burst pressure of the pipe is unchanged, whether under methane pressure or under hydrogen pressure. 


\subsection{Modification of plasticity}

The embrittlement mechanism associated with transport by dislocations is based on the existence of hydrogen trapping in the core and the stress field of dislocations and on the possibility of accelerated transport of hydrogen by dislocations in motion. It is therefore accepted that, under certain conditions, mobile dislocations can accumulate hydrogen on defects which constitute obstacles to their movement. This accumulation of hydrogen combined with the existence of strong stresses associated with the pile-up of dislocations, can favour initiation and/or propagation of a crack. This mechanism supposes an intense trapping of hydrogen on the dislocations, therefore a strong activity of hydrogen in the network at moderate temperature. It also requires good compatibility between the mobility of hydrogen and that of dislocations, therefore low rates of deformation. The local accumulation of hydrogen is favoured by a coplanar movement of the dislocations and depends on the nature and the distribution of the defects in the microstructure.

The latter can, in fact, limit the movement of dislocations or even reduce, by trapping effect, the amount of hydrogen transported. On the contrary, certain reversible traps can behave as sources for mobile dislocations. The microstructure of the material therefore plays an important role. The mechanism of source of mobile dislocations can be described by the mechanism of Franck and Read. Modification of plasticity induces a reduction of elongation at failure particularly for high strength steels, Figure 7.

Elongation at failure $\mathrm{A} \%$

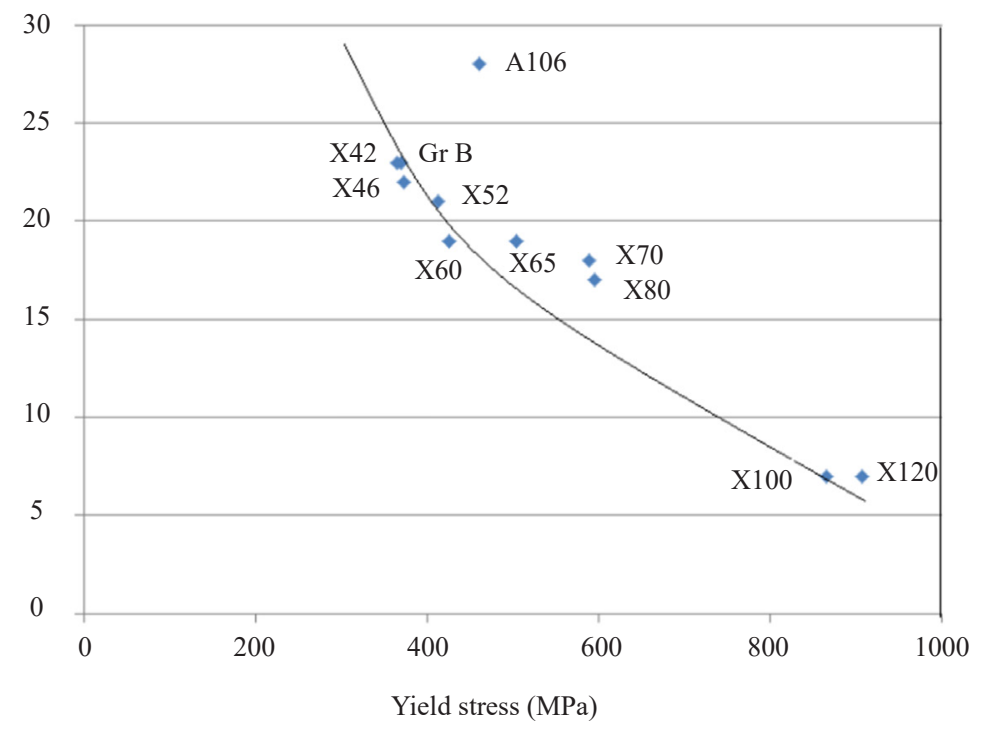

Figure 7. Evolution of elongation at failure for several pipe steels versus yield stress

The micro-cracking mechanism is based on the competition between the emission of dislocations and local decohesion under hydrogen. When a critical concentration of hydrogen is reached in front of the crack, a micro-crack begins there by local lowering of the cohesion stress and blocking of dislocations in the hydrogen-enriched zone. The micro-crack thus formed stops in front of said zone by stress relaxation due to the emission of dislocations. The discontinuous process can thus repeat itself.

In the presence of a very high equivalent hydrogen pressure or under the effect of a supersaturation associated with the sudden change in temperature of a material containing a high quantity of hydrogen, different forms of cracking of steels can be observed in 1 absence of imposed constraint: Blistering, internal cracking. This cracking results from a molecular recombination on defects (micro cavities etc...) which play the role of traps. The hydrogen pressure in the micro cavities can be high enough to cause cracking.

This mechanism is invoked for the formation of blisters, a defect frequently encountered in pipes carrying 
hydrogen, Figure 8. After hydrogen diffusion, its recombination inside the material in gas provokes blister by bulging.

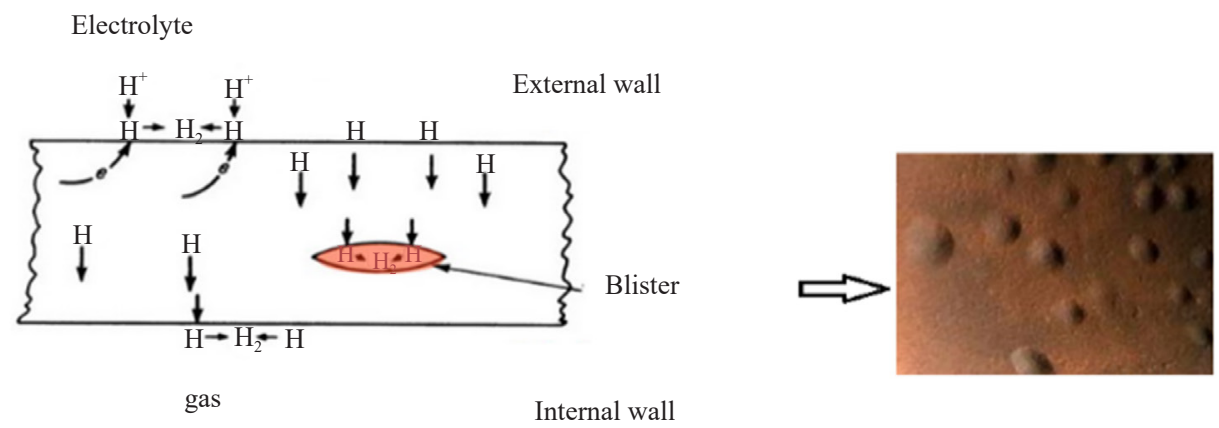

Figure 8. Blistering by internal recombination of hydrogen

\section{Maximum allowable operating pressure}

Transport of hydrogen pure or blend with natural gas needs to ensure that the pipe networks operate safety and in any circumstances for economic, social and environmental reasons. HE is therefore necessary to be taken into account at three levels: design maintenance and surveillance. These operations involve mechanical properties which are affected by HE.

Design is based on yield stress and ultimate strength on a stress based design or elongation at failure for strain based design. Maximum allowable operating pressure calculated from yield stress which is not affected by HE. At first approach cannot be modify when comparing with those use for natural gas pipe design. However, under HE scatter of this mechanical properties increase and this needs to be taken into account by a probabilistic approach.

Strain based design of pipes use for transport of hydrogen pure or blend with natural gas is based on failure elongation with a scattered and affected value. This affects strongly the admissible local strain and the associated safety factor.

During maintenance operations, it should be taken into account that hydrogen embrittlement reduces the fracture toughness and consequently the admissible defect size for a conventional risk probability of $10^{-5}$.

Hydrogen embrittlement reduces crack initiation duration emanating from a defect and considerably accelerates the crack propagation. To address this problem, new monitoring intervals should be calculated and new monitoring scheme needs to take place.

In this paper, only the consequence of HE on stress based design is described. Pipeline design ensures that failure occurs when the strength capacity of the pipe steel is exceeded. This consists of verifying that the membrane stress does not exceed the admissible stress define as the material strength divided by a safety factor.

The principle for calculating the MAOP is based on the so-called boilermaker formula:

$$
p=\sigma e / R
$$

$\mathrm{p}$ is the pressure, $\sigma$ the stress, e the thickness and $\mathrm{R}$ the radius of the pipe. In some codes like ASME [12] calculation formula involves partial safety coefficients that are not necessarily multiplicative, such as the reduction in thickness to be taken into account.

$$
\mathrm{MAOP}=\frac{2 \mathrm{~S}_{y} \mathrm{e}}{\mathrm{D}} \mathrm{f}_{0} \mathrm{E}^{\prime} \mathrm{T}^{\prime} \mathrm{H}_{\mathrm{f}}
$$

S: specified minimum yield strength,

e: nominal thickness,

D: nominal outside diameter, 
$\mathrm{f}_{0}$ : design factor,

E: weld factor of the longitudinal joint,

$\mathrm{T}^{\prime}$ : temperature derating factor,

$\mathrm{H}_{\mathrm{f}}$ : material performance factor,

S: permissible membrane stress,

E': efficiency of the weld joint or quality factor of the original construction code.

For pipe steels, the specified minimum yield strength $\mathrm{S}$ is given from designation of the steel example API 5L X $\left(\sigma_{y, \text { specif }}\right)$ and given by:

$$
\mathrm{S}_{y}=\sigma_{\mathrm{y}, \text { specif }} * \mathrm{f}_{0}
$$

Table 3. Design factor for hydrogen transport by pipes according to [12]

\begin{tabular}{cc}
\hline location & Design factor $\mathrm{f}_{0}$ \\
\hline High constraint & 0.72 \\
Rural & 0.6 \\
Semi-urban & 0.5 \\
Urban & 0.4 \\
\hline
\end{tabular}

ASME [13] proposes some design factor values for pipelines carrying hydrogen according to the different locations in which they are installed. This design factor, the inverse of the safety factor, $f_{s}$ is determined by a deterministic approach based on expert judgment. ASME [12] offers $\mathrm{f}_{0}$ according to four different locations classified according to the number of buildings and the population density indicated in Table 4 below:

For pipes used for hydrogen transport, the highest value of admissible risk [14] is a probability of occurrence of $P_{r}=10^{-5}$.

In general, the probability of an incident and the human, economic or societal consequences of this particular incident are combined into an overall risk factor. The risk associated with pipeline for hydrogen transport is determined using the following general equation:

$$
\begin{aligned}
\text { Risk }= & \text { Frequency of pipeline failure } \times \text { probability of flow lesser than a critical value } \\
& \times \text { probability of ignition } \times \text { probability of the presence of a person } \\
& \times \text { probability of lethal effects greater than a threshold value }
\end{aligned}
$$

When the aforementioned risk is defined as an individual and human risk, the result is the probability of a person becoming a victim in a year. Global risk is therefore the product of all failures and consequences (per year). It is expressed by the probability that a point located near a pipe and at a known distance could be exposed until it reaches an intensity greater than a reference level.

The aim of this paper is to determine the design factor for pipes used for pure or blended hydrogen for 3 different locations: rural, semi-urban and urban. For each case, an admissible risk probability of $10^{-5}$ is assumed. The design factor is therefore computed using the following risk probability equation:

$$
P_{r}(\text { Risk })=P_{r}(\mathrm{~L}) \times \operatorname{Pr}(\mathrm{Q}) \times P_{r}(\mathrm{I}) \times \operatorname{Pr}(\mathrm{LE}) \times P_{r}(\text { pers }) \times \mathrm{L} \times C_{e v} \times C_{r r}
$$

$-P_{r}(\mathrm{~L})$ probability of leakage after failure,

$-P_{r}(\mathrm{Q})$ probability of gas flow lower than prescribed value,

$-P_{r}(\mathrm{I})$ probability of ignition,

$-P_{r}(\mathrm{LE})$ probability of lethal effects greater than a threshold value, 
$-P_{r}$ (pers) probability of the presence of a person,

-L length of the pipeline taken into account,

$-C_{e v}$ coefficient taking into account the location of the pipeline,

$-C_{r r}$ risk reduction factor taking into account risk reduction measures.

In this study, probabilistic design factor $f_{0, p r o}$ associated with 3 locations (rural, urban and sub-urban) are computed and are compared with deterministic design factor $f_{0, \text { det }}$.

\subsection{Leak probability}

Leak probability is calculated according to the following criterion: leak is considered to happen when the service pressure $P_{s}$ exceeds the Maximum Allowable Operating Pressure (MAOP) [2].

$$
p_{s} \geq \mathrm{MAOP}
$$

Maximum Allowable Operating Pressure is based on the simplified formula:

$$
\text { MAOP }=\frac{\sigma_{y}, f_{0} t}{R}
$$

Where $\sigma_{y}$ is the yield stress, $\mathrm{t}$ is thickness and $\mathrm{R}$ is radius of the pipe. $\mathrm{f}_{0}$ is the so-called design factor.

Yield stress $\sigma_{y}$ distribution is determined from 4 tensile tests carried out in the presence of hydrogen while the variation in the thicknesses $t$ and pipe internal radius $R$ are determined from their minimum and maximum tolerances. In this study, tolerances are obtained by the " 3 standard deviations rule". The three stochastic measures $\sigma_{y}, \mathrm{t}$ and $\mathrm{D}=2 \mathrm{R}$ will serve as input variables for the probability calculation which will be performed by the Monte Carlo method. Pipe steel is API 5L X60.

For each input variable, its distribution parameters as well as its type of distribution law are indicated in Table 4.

First, the four main parameters of a distribution such as the mean, the standard deviation, the flattening and symmetry coefficients are compared in order to test the symmetry and the distortion of this distribution. According to Table 4, a positive skewness value indicates that the data set is skewed to the right i.e. the mean is greater than the median. The kurtosis is also greater than zero, which indicates that the central peak is higher and sharper than a normal distribution.

Table 4. Distribution parameters and distribution law associated with each input variable

\begin{tabular}{cccccc}
\hline Variable & Mean $\mu$ & Standard deviation, $\mathrm{S}$ & Skewness & Kurtosis & Distribution law \\
\hline Yield stress & $544 \mathrm{MPa}$ & $24.8 \mathrm{MPa}$ & 0.015 & 3.01 & Normal \\
Thickness & $5.210^{-3} \mathrm{~m}$ & $0.2410^{-3} \mathrm{~m}$ & 0.0014 & -99 & Normal \\
Diameter & $31410^{-3} \mathrm{~m}$ & $0.7910^{-3} \mathrm{~m}$ & -0.001 & 3.00 & Normal \\
MAOP & $17.07 \mathrm{MPa}$ & $1.24 \mathrm{MPa}$ & 0.10 & Normal \\
\hline
\end{tabular}

In order to test whether the character of this sample can be approximated by a known or ideal probability law, the Kolmogorov-Smirnov test is carried out to compare this distribution with a theoretical distribution (values taken as mean and standard deviation are the ones indicated in Table 4).

This test compares the data obtained with a known or theoretical distribution, in this study, normal or the lognormal law. 


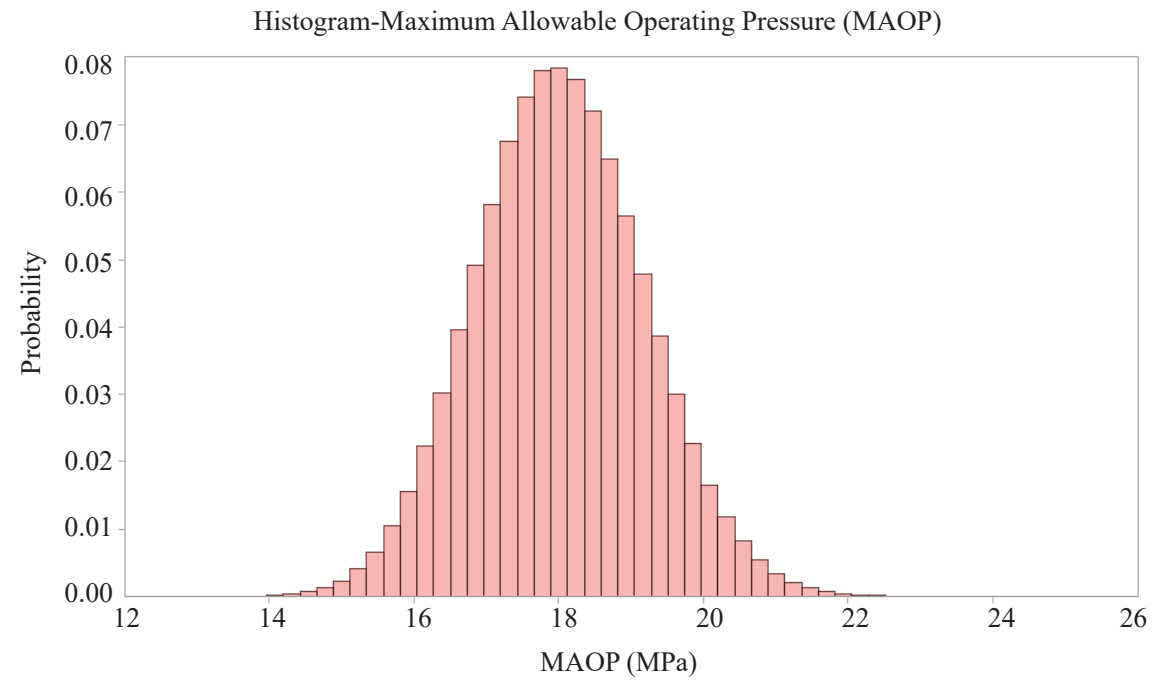

Figure 9. Distribution of the probability density versus MAOP. Pipe thickness5.2 mm Pipe diameter $314 \mathrm{~mm}$

The parameters of the test [15] are as follows:

$-\mathrm{D}_{\mathrm{KS}}$ : The biggest difference between the values from the actual distribution and the theoretical (or ideal) distribution,

$-\alpha$ : Risk of error (fixed at $5 \%$ or 0.05 ),

$-P_{r}:$ probability which measures the degree of certainty which it is possible to invalidate the distribution hypothesis.

Results of which are indicated in Table 5. When comparing $\mathrm{D}_{\mathrm{KS}}$ value, it will be more precise to consider that the distribution approaches a Normal distribution than the Log-normal distribution.

Table 5. The results of the Kolmogorov-Smirnov test for the Normal distribution and the Log-normal distribution

\begin{tabular}{ccc}
\hline & \multicolumn{2}{c}{ Distribution } \\
\cline { 2 - 3 } Paramètres & Normal & Log-normal \\
\hline $\mathrm{D}_{\mathrm{KS}}$ & 0.04 & 1 \\
$\alpha$ & 0.05 & 0.05 \\
$\mathrm{P}_{\mathrm{r}}$ & $<0.0001$ & $<0.0001$ \\
\hline
\end{tabular}

As indicated in Table 6, the value of MAOP which satisfy criterion of Equation (7) decreases as the probability decreases from $10^{-3}$ to $10^{-7}$. A $10^{-5}$ leak probability corresponds to a maximum admissible operating pressure value of 12.26 MPa. This value is considered to be consistent with the value of the operating pressure in the pipeline, which is $5.5 \mathrm{MPa}$.

Table 6. MAOP associated with leak probability

\begin{tabular}{cccccc}
\hline Leak probability & $10^{-3}$ & $10^{-4}$ & $10^{-5}$ & $10^{-6}$ & $10^{-7}$ \\
\hline MAOP $(\mathrm{MPa})$ & 13.41 & 12.68 & 12.04 & 11.47 & 11.95 \\
\hline
\end{tabular}

Assuming that $P_{r}(\mathrm{~L})$ is fixed at $10^{-5}$ for the 3 locations, each MAOP associated to different location is computed 
by finding the correspondence between the value of leak probability $P_{r}(\mathrm{~L})$ with the cumulative frequency distribution obtained from the Monte Carlo simulation Table 7 shows the values of MAOP for each locations:

Table 7. MAOP and leak probability associated with location

\begin{tabular}{cccc}
\hline Location & Rural & Peri-urban & Urban \\
\hline $\mathrm{P}_{\mathrm{r}}(\mathrm{L})$ & $1.25 \times 10^{-4}$ & $6.67 \times 10^{-6}$ & $3.33 \times 10^{-6}$ \\
MAOP $(\mathrm{MPa})$ & 12.5 & 11.7 & 11.5 \\
\hline
\end{tabular}

The partial design factors $\mathrm{f}_{0 \text {. prob, MAOP }}$ are calculated using the following formulae:

$$
\begin{gathered}
\mathrm{f}_{0 . \text { prob, MAOP }} \frac{\text { MAOP }}{\mathrm{P}_{\mathrm{r}, 0.5}} \\
\text { MAOP }<\mathrm{P}_{\mathrm{r}, 0.5}
\end{gathered}
$$

With $\mathrm{P}_{\mathrm{r}, 0.5}$ : median. The safety factor is defined as:

$$
f_{s, \text { MAOP }}=\frac{1}{\mathrm{f}_{0 . \text { prob, MAOP }}}
$$

The values of $\mathrm{f}_{0 \text {.prob }}$ decreases as the number of population in the location increases, as shown in Table 8 .

Table 8. Values of partial MAOP design and safety factor associated with location

\begin{tabular}{cccc}
\hline Location & Rural & Peri-urban & Urban \\
\hline $\mathrm{f}_{0, \text { prob, MAOP }}$ & 0.8 & 0.7 & 0.7 \\
$\mathrm{f}_{\text {s,prob, MAOP }}$ & 1.43 & 1.43 & 1.43 \\
\hline
\end{tabular}

\subsection{Gas flow rate emanating from hole and probability of flow rate}

In order to evaluate the probability of gas flow greater than a critical value $P_{r}(\mathrm{Q})$, it is necessary to calculate the flow emanating from a pipe aperture. The size of the aperture needs to be identified. To identify the aperture, a method base on the critical Crack Tip Opening Angle (CTOA) is used [13].

The CTOA $\Psi$ is defined as the angle between the crack faces of a growing crack. Practically, its definition is based on crack tip opening displacement $\delta$ at a distance $d$ of the order of $1 \mathrm{~mm}$ (Figure 10).

$$
\Psi=\operatorname{arctg}\left(\frac{\delta}{2 d}\right)
$$

Conditions of stable crack growth require that the rate of change of the crack driving force $\delta_{R}$ with increasing crack length $\Delta \mathrm{a}$ to be smaller than the increase of crack growth resistance expressed in terms of crack opening displacement $\delta$ :

$$
\frac{d \delta}{d a} \leq \frac{d \delta_{R}}{d a}
$$


It can be seen that on the R curve $\delta_{R}=\mathrm{f}(\mathrm{a})$ that the left term in (13) is precisely the CTOA that is constant in the linear part of the R curve (Figure 11).

$$
\frac{d \delta_{R}}{d a}=C T O A
$$

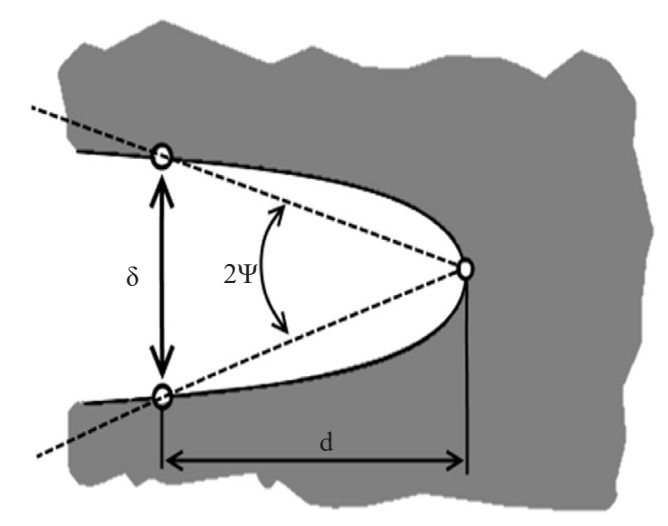

Figure 10. Definition of CTOA on the curved crack profile

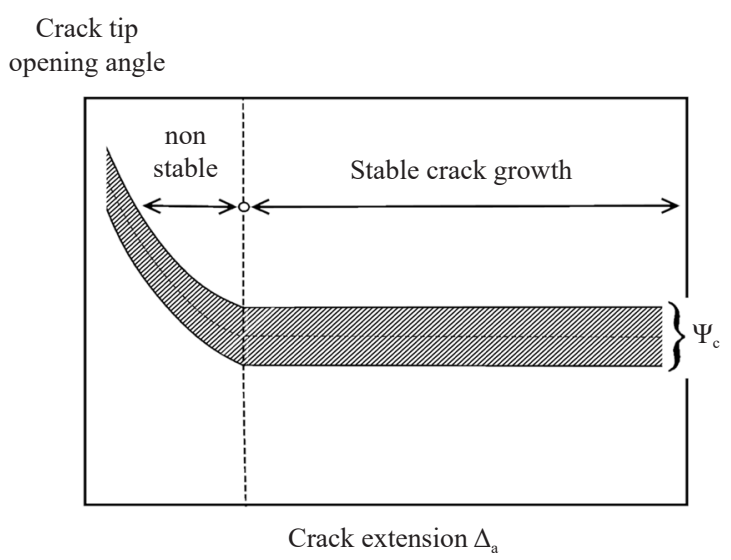

Figure 11. Evolution of CTOA during crack extension

Gas pipeline fracture initiation is usually followed by extended running crack propagation. This occurs when driving force energy, caused by internal pipe pressure, overcomes the crack propagation resistance.

Conditions for crack propagation or arrest are given by a coupled fluid-structure problem. In terms of a limit state design, the arrest pressure can be predicted by solving Equation (15) between the fracture resistance and component stress, which depend on the pipeline dimension, internal pressure and material strength.

$$
\left(\sigma_{i j}(p)\right)=\left(\sigma_{i j, c}\left(p_{a r}\right)\right)
$$

Where $p_{a r}$ is arrest pressure. Condition of arrest can be transformed by the new following condition:

$$
\operatorname{CTOA}(p)=\operatorname{CTOA}_{\mathrm{C}}\left(\mathrm{p}_{\mathrm{ar}}\right)
$$


Where CTOA is the crack tip opening angle induced by the current pressure and $\mathrm{CTOA}_{\mathrm{c}}$ the fracture resistance. For API 5L X52 steel, a value of $\mathrm{CTOA}_{c}=13.7^{\circ}$ is obtained. This value is in agreement with value given by [15].

The value of the gas flow passing through hole caused by pipe failure is related to the size of the breach. In order to obtain the breach size, Finite Element Method has been use in order to describe the phenomenon of crack arrest and to identify its dimensions i.e. length $2 \mathrm{c}$ and width $2 \mathrm{a}$ assuming that its shape is elliptical. Failure emanates from a pipe defect at the service pressure (55 bar in this study) and propagates in the intact pipe at constant service pressure.

Crack arrest criterion is given by Equation (16) based on Crack Tip Opening Angle CTOA. It is described in $\$ 2$ and more widely in [16]. The pipe's dimension are diameter $315 \mathrm{~mm}$ and thickness $5.2 \mathrm{~mm}$. For the steel pipe API X52, the critical value of CTOA is: $\mathrm{CTOA}_{\mathrm{c}}=13.7^{\circ}$. The stress-strain behaviour of the material is assumed to be elasto-plastic with strain-hardening and described in [18]. Figure 12 gives a description of the breach obtained by modelling the crack arrest phenomenon. The length of the breach is $2 \mathrm{c}: \sim 400 \mathrm{~mm}$ and the width $2 \mathrm{a}: \sim 20 \mathrm{~mm}$.

The gas flow is computed by an analytical method. The pipe pressure is assumed to be constant despite the presence of a leak and the gas flow is considered supersonic.

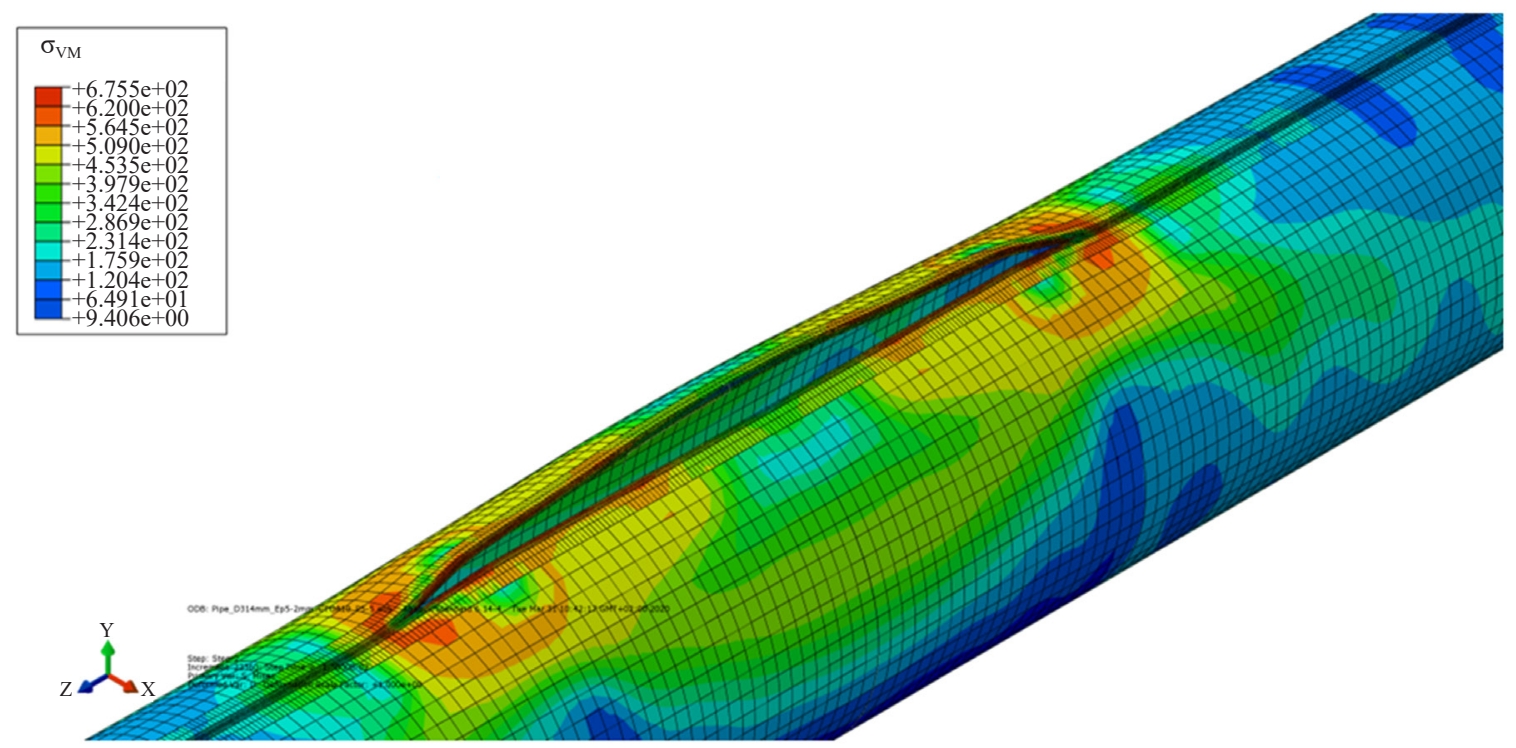

Note: Pipe diameter and thickness, date, incremental step and scale factor are also reported in Figure 12 near the breach

Figure 12. Breach obtained by the burst of a pipe made in steel API 5L X52, diameter $315 \mathrm{~mm}$ and thickness $5.2 \mathrm{~mm}$ with method described in [13]

For analytical method, the gas leaking from a small hole behaves like an ideal gas and the leak rate can be calculated from Equation (17) [17]:

$$
\left.\mathrm{q}=\mathrm{pS} \sqrt{\frac{2 \mathrm{nM}}{(\mathrm{n}-1) \mathrm{GT}} *\left(\frac{\left(\frac{\mathrm{p}_{0}}{\mathrm{p}}\right)^{\mathrm{n}}}{2}-\frac{\left(\frac{\left(\mathrm{p}_{0}\right.}{\mathrm{p}}\right)^{\mathrm{n}+1}}{\mathrm{n}}\right.}\right)
$$

q: flow rate of the leak in $\mathrm{kg} / \mathrm{s}$,

$\mathrm{p}$ : internal pressure in $\mathrm{Pa}(5500000 \mathrm{~Pa})$,

$\mathrm{S}$ : crack area in $\mathrm{m}^{2}(0.025)$,

$\mathrm{M}$ : molar mass of hydrogen in $\mathrm{kg} / \mathrm{mol}$, 
G: ideal gas constant $\mathrm{J} /(\mathrm{mol} / \mathrm{K})$,

$\mathrm{T}$ : gas temperature in the pipe,

$p_{0}$ : atmospheric pressure in $\mathrm{Pa}$,

n: adiabatic coefficient of hydrogen.

With the above-mentioned value the leak rate, $\mathrm{q}$ is equal to $15.83 \mathrm{~kg} / \mathrm{s}$.

\subsection{Probability of ignition $P_{r}(I)$}

On pipe carrying flammable, combustible or toxic products, a leak is considered to be originated from a breach. For our case, the leak origin is an ellipsoidal crack which has the dimension length $2 \mathrm{c}$ and width 2a. The crack length is defined from the condition of crack arrest given by the CTOA criterion and the width by the associated crack opening displacement at the middle of the crack.

According to BEVI [17], INERIS [18] and the Canvey report [19], the flow rate of a leak has an influence on the probability of immediate ignition.

Based on the leak rate of $16 \mathrm{~kg} / \mathrm{s}$ calculated based on Equation (17), a probability of 0.5 suggested by BEVI [17] is taken into account and the upper limit of $100 \mathrm{~kg} / \mathrm{s}$ is fixed as the reference value of leak rate.

\subsection{Probability of presence of a person, $P_{r}$ (pers)}

Dangerous phenomena resulting from a pipe leak can have serious consequences for persons in nearby area. Since the results depend on the substance properties and the transport conditions, the damage could extend over several meters or even several hundred meters. The hazard study makes it possible to determine these effect areas and to define, if necessary, the risk reduction measures to be implemented.

INERIS [18] proposed delayed ignition probability values for a long-term (greater than 30 seconds) and short-term (less than 30 seconds) leak. Values of probability of presence of person, $\mathrm{P}_{\mathrm{r}}$ (pers) according to the 3 locations defined in our study i.e. rural, semi-urban and the urban are given in [19].

INERIS suggested: 0.1 associated with zone A where staffs are absent and 1 associated with zone $\mathrm{C}$ with regular presence of staff. For the semi-urban are which is located between these two extreme limits, we estimated the $\mathrm{P}_{\mathrm{r}}(\mathrm{pers})$ to be equal to 0.5 . Table 9 summarizes selected values for $P_{r}$ (pers).

Table 9. Values of $P_{r}$ (pers) according to location

\begin{tabular}{cc}
\hline location & $\mathrm{P}_{\mathrm{r}}($ pers $)$ \\
\hline Rural & 0.1 \\
Peri-urban & 0.5 \\
Urban & 1 \\
\hline
\end{tabular}

\subsection{Probability of letal effect $P_{r}(L E)$}

Hydrogen has a large range of flammability in air and a low ignition energy. An atmosphere that is too rich or too poor in hydrogen cannot allow it to ignite or explode. Its main characteristics are shown in Table 10.

Table 10. Ignition and flammability of hydrogen

\begin{tabular}{cccc}
\hline $\begin{array}{c}\text { Auto-ignition temperature in air } \\
\left({ }^{\circ} \mathrm{C}\right)\end{array}$ & $\begin{array}{c}\text { Flammability limit in air } \\
(\% \mathrm{vol})\end{array}$ & $\begin{array}{c}\text { Minimum ignition energy } \\
(\mathrm{mJ})\end{array}$ & $\begin{array}{c}\text { Burning rate in air } \\
(\mathrm{m} / \mathrm{s})\end{array}$ \\
\hline 585 & $4-75$ & 0.02 & 2.7 \\
\hline
\end{tabular}


A cloud of flammable gas is formed from a mixture of hydrogen and ambient air within a few seconds after hydrogen release. Due to its very high burning rate, this cloud could produce an explosion. It disperses quickly and can establish a quasi-stable gas jet. If the released gas ignites immediately, a torch-shape flame is produced. In the case of delayed ignition, an explosion of the gas cloud is possible.

If the source of a leak is a small hole and the fire is a flaming jet, the received heat flux at a certain distance from the fire source and per unit area, can be calculated as follows [17]:

$$
Q=\frac{\gamma \tau q H_{c}}{4 \pi r^{2}}
$$

Q: heat flux in $\mathrm{W} / \mathrm{m}^{2}$,

$\gamma$ : radiation coefficient,

$\tau$ : atmospheric transmissivity,

q: leakage rate in $\mathrm{kg} / \mathrm{s}$,

$\mathrm{H}_{\mathrm{c}}$ : heat of combustion in $\mathrm{J} / \mathrm{kg}$,

$\mathrm{r}$ : radial distance between the fire and the place of interest.

The flow rate, q can also be expressed by the effective gas release rate $q_{e f}$ :

$$
\mathrm{q}_{\mathrm{ef}}=6.47 \times 10^{-4} \mathrm{~A}_{\mathrm{p}} \alpha \mathrm{p}_{\mathrm{s}} \times \max \left(0.3 ; \frac{1}{\sqrt{1+4.18 \times 10^{-3} \alpha^{2}(\mathrm{~L}) / \mathrm{D}}}\right)
$$

$\alpha:$ size of the dimensionless hole $\alpha=\frac{A_{h \times C_{D}}}{A_{p}}$,
$\mathrm{A}_{\mathrm{h}}$ : area of the leak in $\mathrm{m}^{2}$,

$A_{p}$ : pipe section in $\mathrm{m}^{2}$,

$\mathrm{C}_{\mathrm{D}}$ : rejection coefficient i.e. ratio between the real and theoretical discharge flows,

$\mathrm{p}_{\mathrm{s}}$ : operating pressure in $\mathrm{Pa}$,

$\mathrm{L}$ : length of the pipe from the gas supply station to the point of fire in $\mathrm{m}$.

The flow value used in the calculation is $100 \mathrm{~kg} / \mathrm{s}$ which corresponds to the reference value of leakage flow. The radial distance between the light and the place of interest, $\mathrm{r}$ is taken equal to the previously selected effect: $5 \mathrm{~m}$. Therefore, the computed value of the heat flux is $13.38 \mathrm{~kW} / \mathrm{m}^{2}$.

In regulatory studies, three critical thresholds causing harmful effects on humans are used:

- Threshold for Irreversible Effects (IET) corresponding to the zone of significant dangers for human life: $3 \mathrm{~kW} / \mathrm{m}^{2}$ for thermal effects, 50 mbar for overpressure effects.

- Threshold of the First Lethal Effects (FLE) corresponding to the area of serious dangers for human life, $5 \mathrm{~kW} / \mathrm{m}^{2}$ for thermal effects, 140 mbar for overpressure effects.

-Threshold for Significant Lethal Effects (SLE) corresponding to the zone of very serious dangers for human life, $8 \mathrm{~kW} / \mathrm{m}^{2}$ for thermal effects, 200 mbar for overpressure effects [20].

The probability of death due to thermal effect can be estimated using a probit function (Equation (20)) and the probability of death, $\mathrm{P}_{\text {death }}$ (Equation (21)) proposed by Tsao \& Perry [21]:

$$
\begin{gathered}
\text { Pro }=-12.8+2.56 \operatorname{Ln}\left(\frac{\mathrm{Q}^{4}}{3} \mathrm{t}\right) \\
\mathrm{P}_{\text {death }}=\frac{1}{\sqrt{2 \pi}} \int \mathrm{e}^{-0.5 \mathrm{~s}^{2}} \mathrm{ds}
\end{gathered}
$$


Q: heat flux in $\mathrm{kW} / \mathrm{m}^{2}\left(8.56 \mathrm{~kW} / \mathrm{m}^{2}\right)$,

t: duration of exposure in $\mathrm{s}$.

The value of probit for lethal thermal effect is 3.23 and the associated probability of death, $\mathrm{P}_{\text {death }}=0.04$.

\subsection{Risk reduction $C_{r r}$ and environment coefficient $C_{e v}$}

The pipeline carrying gas is often buried or exposed to the open air. The work of monitoring or maintaining the pipeline may sometimes result in pipeline-related incidents, for example rupture. Statistics [22] indicate that the risk factor "Works by nearby third parties (external aggressions and accidental stinging)" is responsible for more than 56\% of the accidents recorded on the transport pipeline network. Consequently, a set of preventive measures is implemented to reduce this factor of third party work, amongst which a risk reduction coefficient $C_{r r}$ making it possible to assess the effectiveness of the measures is integrated into the risk probability equation (Equation (1)). Two limit values of the risk coefficient are used for this study: $C_{r r}=0.01$ for optimum protection and $C_{r r}=1$ for cases where compensatory measures are not imposed.

Gas network passes through different regions and altitudes which require additional measures intended to reinforce the safety of the pipes. In the risk analysis, the environment around the pipeline has an influence on risk probability and it is translated as environment, coefficient $\mathrm{C}_{\mathrm{ev}}$. This coefficient is greater than or less than 1 depending on the aggravating or improving nature of the environment. GESIP [23] proposes coefficients according different environments in Table 10.

In this study, three areas were defined i.e. rural, semi-urban and urban. The values of the environmental coefficient used are $\mathrm{C}_{\mathrm{ev}}=0.8$ for the rural area and $\mathrm{C}_{\mathrm{ev}}=3$ for both the semi-urban and urban areas.

\section{Discussion}

Table 11 gives a summary of parameter values of Equation (1) for the (3) locations (rural, peri-urban and urban). This table gives also the probability of leak $P_{r}(L)$, here leak is considered to happen when the service pressure $p_{s}$ overcomes Maximum Allowable Operating Pressure (MAOP) and associated with a conventional probability of risk of $10^{-5}$.

This probability is generally recommended by codes as a compromise between safety and costs. This table gives also value of MAOP for the 3 locations, where the values are relatively close. The last line gives a round off value of design factor computed by probabilistic method $\mathrm{f}_{0, \text { prob }}$.

Table 11. Parameter values of Equation (6) for the (3) locations (rural, peri-urban and urban)

\begin{tabular}{cccc}
\hline Location & Rural & Peri-urban & Urban \\
\hline $\operatorname{Pr}($ Risque $)$ & & 0.00001 & \\
$\mathrm{~L}(\mathrm{~km})$ & & 100 & \\
$\mathrm{C}_{\mathrm{rr}}$ & & 1 & \\
$\operatorname{Pr}(\mathrm{Q})$ & 0.5 & \\
$\operatorname{Pr}(\mathrm{I})$ & 0.5 & \\
$\operatorname{Pr}(\mathrm{EF})$ & & 0.04 & 1 \\
$\operatorname{Pr}(\operatorname{Pers})$ & 0.1 & 0.5 & 3 \\
$\mathrm{C}_{\text {ev }}$ & 0.8 & 3 & $3.33 \times 10^{-6}$ \\
$\operatorname{Pr}(\mathrm{L})$ & $1.25 \times 10^{-4}$ & $6.67 \times 10^{-6}$ & 12.76 \\
$\operatorname{MAOP}(\mathrm{MPa})$ & 13.75 & 12.94 & 0.7 \\
$\mathrm{f}_{0, \text { prob }}$ & 0.8 & 0.7 & \\
\hline
\end{tabular}


Table 12 shows a comparison between probabilistic design factor $\mathrm{f}_{0 \text {,prob }}$ given by the present method and deterministic one $\mathrm{f}_{0 \text {,det }}$ given by [12]. One notes that deterministic values are more conservative and differs between the 3 locations. Unfortunately, no description was found in [12] which lead to such value of deterministic design factor.

However, definitive conclusion are limited due to the fact that this study has been made for a given pipe geometry and a particular pipe steel API 5L X60.

Table 12. Probabilistic design factor $\mathrm{f}_{0, \text { prob }}$ deterministic design factor $\mathrm{f}_{0, \text { det }}$

\begin{tabular}{cccc}
\hline & Rural & Peri-urban & Urban \\
\hline $\mathrm{f}_{0, \text { prob }}$ & 0.8 & 0.7 & 0.7 \\
$\mathrm{f}_{0, \text { det }}$ & 0.6 & 0.5 & 0.4 \\
\hline
\end{tabular}

However, definite conclusions are limited due to the fact that this study has been carried out for a given dimension of pipe and a particular steel pipe which is X52. Authors think that by expanding this study to a larger context such as on other dimension of pipes and other types of steel can modify strongly the conclusions.

Equation (6) is subjected to the Coefficient Of Variation (COV) of the pipe steels. Material properties have a strong influence on the design factor as one can see in Table12 and Figure 13. The influence of COV of a range [0.05-0.20] on MAOP, indicates that for urban area, the MAOP decreases by $90 \%$ and design factor by $85 \%$.

Modern steels manufactured with recent process have low inclusion content. The low scatter in mechanical properties with COV less than 0.1 ensures a design factor greater than 0.5 . The European pipe networks include some very old part with low strength vintage steels with higher COV. Therefore, the usage of a uniform design factor for each part is problematic. Using the lower value for conservative reason induces an economical problem because with a low service pressure the gas flow is considerably reduced. If we assume that that the economical threshold for MAOP, called MAOP* is $50 \mathrm{MPa}$, one cannot tolerate in the pipe networks, some part with vintage steels exhibiting a COV greater than 0.15 , see Figure 6 .

Table 13. Influence of COV of yield stress on MAOP according to location

\begin{tabular}{cccc}
\hline Location & COV & MAOP $(\mathrm{MPa})$ & $\mathrm{f}_{0, \text { prob }}$ \\
\hline Rural & & 13.7 & 0.8 \\
Peri-urban & 0.05 & 12.9 & 0.7 \\
Urban & & 12.8 & 0.7 \\
Rural & 0.1 & 10.7 & 0.6 \\
Peri-urban & & 9.4 & 0.5 \\
Rural & & 9.1 & 0.5 \\
Country & 0.15 & 7.7 & 0.4 \\
Peri-urban & & 5.7 & 0.3 \\
Urban & & 5.3 & 0.3 \\
Rural & 0.2 & 4.5 & 0.2 \\
Peri-urban & & 1.9 & 0.1 \\
Urban & 1.4 & 0.1 \\
\hline
\end{tabular}

The microstructure of steel plays an important role in stress corrosion and hydrogen embrittlement. A relationship seems to exist between the susceptibility to hydrogen embrittlement and the capacity of different characteristics of the microstructure of steel to trap hydrogen. The slower the diffusion of hydrogen, the more effective the traps and the 
greater the possibility of training and development of hydrogen collectors according to Oriani [8]. It is energetically more favorable for hydrogen to exist in a trapping site or in an interstitial site of the network if the temperature is low (lower than $300^{\circ} \mathrm{C}$ ) [9].

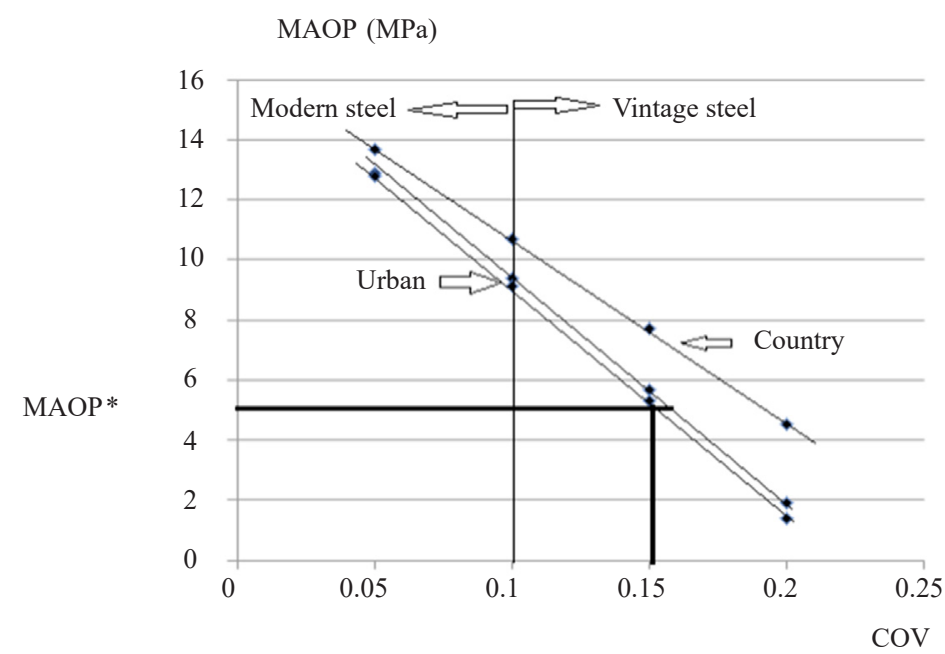

Figure 13. Influence of COV of yield stress on MAOP according to environment, in the case of modern and vintage steels

In Europe, a significant part of the old pipe networks remains as it is manufactured in quality tubes B, X46 and X52 while knowing that 3 of these grades re-represent around 70\% of the diversity of this network, at know: Grade B, X52 and X60. Manufacturing technologies for high yield strength steels (HYSS) improved rapidly from 1970 often due to increased demand for the construction of gas and oil pipelines.

There are many sources of structural defects that act as traps such as grain boundaries, micro-voids, dislocations, ferrite-carbide interfaces, non-metallic inclusions (oxide, $\mathrm{TiC}, \mathrm{MnS}$, etc.).

\section{Conclusion}

The probabilistic design factor $\mathrm{f}_{0 \text {,prob }}$ is calculated from a risk probability equation, $\mathrm{P}_{\mathrm{r}}(\mathrm{Risk})$ which consists of 8 terms. This approach requires knowledge of material properties such as the yield stress and the crack extension resistance as $\mathrm{CTOA}_{\mathrm{C}}$ used for the probability of failure and the size of the breach under service pressure. Other probabilities values and coefficients assigned by expert opinion as proposed by INERIS and BEVI.

This approach is based on assumption of a risk $10^{-5}$ probability, this value is considered as a good compromise between safety and cost.

3 design factors have been computed according to each location, rural, peri-urban and urban. These design factors does not differs very much from one location to another. This might due to the number of terms in the risk probability equation which varies along with the environment, the coefficients taking into account the pipeline environment, $\mathrm{C}_{\mathrm{ev}}$ and the probability of the presence of a person, $\mathrm{P}_{\mathrm{r}}(\mathrm{Pers})$.

Other coefficients such as the length of the pipe $\mathrm{L}$ and coefficient of risk reduction and other probabilities are identical for each location. The comparison between probabilistic $\mathrm{f}_{0 \text {, prob }}$ and deterministic values proposed by ASME noted as $\mathrm{f}_{0 \text {,det }}$, shows that $\mathrm{f}_{0 \text {,prob }}$ are less conservative than ASME. However, it is difficult to justify these discrepancies because $\mathrm{f}_{0, \mathrm{det}}$ are proposed by experts and no written reasoning was found behind the proposed values.

Design factors influence on the one hand the choice of maximum admissible operating pressure and on the other hand the pipe thickness. Therefore, they have consequences on the cost of the pipelines and the amount of gas flow i.e. the profitability of the pipelines. 


\section{Conflict of interest}

The authors declare no conflict of interest.

\section{References}

[1] O. Florisson, "Preparing for the hydrogen economy by using the existing natural gas system as a catalyst," NaturalHy project Report, 2010. Available: http://www.naturalhy.net/docs/project_reports.

[2] J. K. Mijim, G. Pluvinage, J. Capelle, Z. Azari, and M. Benamara, "Probabilistic design factors for pipes used for hydrogen transport," International Journal of Hydrogen Energy, 2020. Available: https://doi.org/10.1016/ j.ijhydene.2020.09.106.

[3] W. H. Johnson, "On some remarkable changes produced in iron and steel by the action of hydrogen and acids," Proceedings of the Royal Society of London, vol. 23, pp. 168-179, 1875.

[4] Y. Liang, P. Sofronis, and N. Aravas, "On the effect of hydrogen on plastic instabilities in metals," Acta Materialia, vol. 51, no. 9, pp. 2717-2730, 2003.

[5] E. A. Steigerwald, F. W. Schaller, and A. R. Troiano, "The role of stress in hydrogen induced delayed failure," Trans Metall Soc AIME, vol. 218, pp. 832, 1960.

[6] T. Magnin, "Corrosion fatigue mechanisms of metallic alloys," Revue de Metallurgie (Paris), vol. 99, no. 5, pp. 423-432, 2002.

[7] S. Charca Mamani, "Study of hydrogen permeation and diffusion in steels: Predictive model for determination of desorbed hydrogen concentration," Doctorate thesis, University of Puerto Rico Mayagüez Campus, Mayagüez, Puerto Rico, 2005.

[8] R. A. Oriani, "Whitney award lecture-1987: Hydrogen-the versatile embrittler," Corrosion, vol. 43, no. 7, pp. 390, 1987.

[9] P. Sofronis, Y. Liang, and N. Aravas, "Hydrogen induced shear localisation of the plastic flow in metals and alloys," Eur. J. Mech. A/Solids, vol. 20, no. 6, pp. 857-872, 2001.

[10] J. Capelle, I. Dmytrakh, and G. Pluvinage, "Electrochemical hydrogen absorption of API X52 steel and its effect on local fracture emanating from notches," Journal of Structural integrity and Life, vol. 9, no. 1, pp. 3-8, 2009.

[11] J. Capelle, "Study of the harmfulness of a scratch-type defect on a pipe intended for the transport of the natural gas-hydrogen mixture," Thesis at the University of Metz, 2008.

[12] American Society of Mechanical Engineers (ASME), Hydrogen Piping and Pipelines. New York: American Society of Mechanical Engineers, 2012, pp. 258.

[13] M. B. Amara, J. Capelle, Z. Azari, and G. Pluvinage, "Modelling crack propagation and arrest in gas pipes using CTOA criterion," Journal of Pipes and Engineering, vol. 15, pp. 243-256, 2016.

[14] S. Li, C. Cheng, and G. Pu, "QRA-Grid: Quantitative risk analysis and grid-based pre-warning model for urban natural gas pipeline," International Journal Of Geo-Information, vol. 8, no. 3, pp. 122-131, 2019.

[15] Ph. P. Darcis, C. N. McCowan, H. Windhoff, J. D. McColskey, and T. A. Siewert, "Crack tip opening angle measurement methods for five pipeline steels," Engineering Fracture Mechanics, vol. 75, no. 8, pp. 2453-2468, 2008.

[16] J. Capelle, J. Gilgert, I. Dmytrakh, and G. Pluvinage, "Sensitivity of pipelines with steel API X52 to hydrogen embrittlement," Journal of Hydrogen Energy, vol. 33, no. 22, pp. 7060-7641, 2008.

[17] RIVM, "Reference manual BEVI risk assessments Version 3.2," National Institute of Public Health and the Environment (RIVM), 2009.

[18] INERIS DRA 71, "Operation B Proposal of a semi-quantitative method for evaluating the probabilities of inflammation," Study report, 2015.

[19] C. J. H. van den Bosch, R. A. P. M. Weterings, "Methods for the calculation of physical effects," CPR 14 E, 3rd Edition, 1997. Available: http://content.publicatiereeksgevaarlijkestoffen.nl/documents/PGS2/PGS2-1997-v0.1physical-effects.pdf.

[20] J. L. Seveque, "ICPE hazard study-Scenario analysis," Engineering techniques, 2006.

[21] C. K. Tsao and W. W. Perry, "Modifications to the vulnerability model: A simulation model for assessing damage resulting from marine spills (vm4)," Ada-075-231 US Coast Guard, 1979.

[22] EGIG, "7th Report of European gas pipeline incident data group," EGIG report 1970-2007, Gas Pipeline Incidents. pp. 1-33, 2008. Available: http://www.EGIG.nl.

[23] GESIP. "Methodological guide for carrying out a study of safety concerning a transport pipeline (liquid or liquefied hydrocarbons, fuel gases and chemicals)," Rapport n²008/01, 2014. 